\title{
“ARE YOU IN YOUR BODY?!”. THE STUDY OF BIOPOLITICAL INTERFACE DESIGN
}

\begin{abstract}
Alexander S. Lenkevich
Research Centre for Media Philosophy; Laboratory for Computer Games Research; ITMO University. St. Petersburg, Russia. Email: a_lenkevich[at]mail.ru
\end{abstract}

\begin{abstract}
The article considers biopolitical design of interfaces in terms of computer games: the player's body is constructed with the help of a variety of technical instances that support gameplay (for instance, gamepads, haptic controllers, virtual reality devices). Through the interaction with interfaces, the new patterns of sensuality are formed, namely, the new forms of tactile communication with media. The article demonstrates the distinction between the representation of biopolitical processes in games (for instance, in Plague. Inc. and Bio. Inc.) and the process of incorporating biopolitical procedures into technical gaming devices, and through them into our bodies and lifestyle. The setting and narratives of games often tend to rely on biopolitical images. However, the processes that take place in our body during the game are more important than those that are presented on the screen: the new controllers increasingly take into account the physical state of the player in order to regulate the level of difficulty, promising not only entertainment but also care. The article raises the question of what the body feels and does not feel when it is included into the game, since the existing interfaces and controllers allow us to simulate a complex perceptual experience which includes not only audiovisual elements, but also touch, smell and so forth. After all, the (self-) control practices embedded in game controllers allow us to view them as technical dispositives through which we master the bodies of the future. The author of the article proposes the concept of a "touch-image" which captures a new dimension of hi-tech sensibility.
\end{abstract}

\section{Keywords}

computer games; body; interfaces; controllers; biopolitics; DualSense; media; digital sensibility; body imagination; touch-image

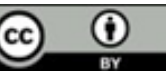

This work is licensed under a Creative Commons «Attribution» 4.0 International License 


\title{
«ТЫ В СВОЕМ ТЕЛЕ?!». ИССЛЕДОВАНИЕ БИОПОЛИТИЧЕСКОГО ДИЗАЙНА ИНТЕРФЕЙСОВ
}

\section{Ленкевич Александр Сергеевич}

(а) Исследовательский центр медиафилософии; Лаборатория исследований компьютерных игр (ЛИКИ); Университет ИТМО. Санкт-Петербург, Россия. Email: a_lenkevich[at]mail.ru

\begin{abstract}
Аннотация
В статье рассматривается биополитический дизайн интерфейсов на примере компьютерных игр: тело игрока конструируется с помощью разнообразных технических инстанций, поддерживающих геймплей (геймпады, хаптические контроллеры, девайсы для виртуальной реальности и т. п.). Через взаимодействие с интерфейсами формируются новые паттерны чувственности, в частности, новые формы тактильной коммуникации с медиа. В статье проводится различие между репрезентацией биополитических процессов в играх (например, в Plague.Inc. и Bio.Inc.) и процессом инсталляции биополитических процедур в технические игровые устройства, а через них - в наши тела, в наш образ жизни и т. д. Сеттинг и нарративы игр часто опираются на биополитические образы, но важнее процессы, происходящие с нашим телом во время игры, а не те, что представлены на экране: новые контроллеры все чаще учитывают физическое состояние игрока, чтобы регулировать уровень сложности, сулят не просто развлечение, но вместе с ним - заботу. В статье поднимается вопрос о том, что чувствует и что не чувствует тело, включенное в игру, поскольку существующие интерфейсы и контроллеры позволяют моделировать сложный опыт восприятия, в который входят не только аудиовизуальные элементы, но и осязание, запах и т.д. В конечном счете практики (само)контроля, вшитые в игровые контроллеры, позволяют рассмотреть их как технические диспозитивы, через которые мы осваиваем тела будущего. В статье предлагается концепт «образ-прикосновение», схватывающий новое измерение высокотехнологической чувственности.
\end{abstract}

\section{Ключевые слова}

компьютерные игры; тело; интерфейсы; контроллеры; биополитика; DualSense; медиа; цифровая чувственность; воображение тела; образ-прикосновение 


\section{КАРТА ЧТЕНИЯ (ВМЕСТО ВВЕДЕНИЯ) ${ }^{1}$}

Вообразим картину: при проверке банковских операций вы обнаруживаете списание внушительной суммы на оплату перцептивных впечатлений - вкусовых, тактильных, слуховых, зрительных, обонятельных и других. Более того, средств на погашение счета в следующем месяце у вас не хватит, поэтому перцептивный траффик ограничивается или даже блокируется. Эта картина кажется фантастической, если понимать перцепцию как нечто естественное/природное. Но наша перцепция (да и тело в целом) представляет собой конструкт, который зависит от определенных техник ${ }^{2}$, технических (и властных) инстанций, диспозитивов ${ }^{3}$. И раз перцепция напрямую связана с техническими аппаратами, ее можно контролировать: так, если вы хотите чувствовать сейсмические колебания Земли, как художница Мун Рибас, или усилить слух, чтобы слышать то, что происходит на расстоянии в тысячи километров, как Супермен или пушкинский пророк (который внемлет «неба содроганье, / И горний ангелов полет, / И гад морских подводный ход, / И дольней лозы прозябанье»), вам следует обзавестись специальными гаджетами.

Надо признать, что массовая культура уже продумывает этот сценарий: в сериале «Загрузка» (Upload, 2020) оцифрованный герой после смерти попадает в технически сконструированный «рай», виртуальную симуляцию, траффик впечатлений в которой стоит огромных денег (если их нет, пользователь получает аккаунт экономкласса с крайне ограниченным функционалом). В ироничном ключе подобные образы создавал и Ф. К. Дик: например, в романе «Убик» (Ubik, 1969) персонажи платят практически за все, в том числе за открытие и закрытие двери в свою квартиру, дверь даже может подать в суд на жильца, если он задерживает оплату. Продолжим фантазию: кожа подает на нас в суд после неуплаты счета за тактильный опыт (сценарий не столь фантастический, если вспомнить, что современные

1 Автор составил «карту чтения», прислушавшись к советам рецензентов, поскольку ее наличие упрощает движение по территории текста. Расширение возможностей чтения (да и письма) в наше время - в эпоху форматов и дедлайнов - превращается фактически в политическую задачу. Читатель волен эту «карту» пропустить и сразу перейти к «мясу» статьи.

2 Например, культурно настраивается боль. Исследованию этого феномена, производительной силе боли (Хайдарова, 2013), а также связи боли с топологической рефлексией, экстремальными практиками тела, проживанием пространства (Савчук, 2012) посвящены отдельные работы. Закономерно, что опыт боли, купированный эстетикой всеобщей анестезии, в превращенной форме возвращается через кино, литературу, театр, компьютерные игры.

3 Например, П. Пресьядо рассматривает «три типа властных технологий» в отношении конструирования тела (некропатриархальный, гетеросексуально-колониальный, фармакопорнографический), каждый из которых задает свои стандарты чувственности, формы сегрегации и контроля, способы фабрикации тел (Пресьядо, 2021). 
гаджеты, которые как раз дополняют и переопределяют функции кожи, т. е. переводят тактильный опыт в технически-коммерческий формат, могут требовать за это плату). Критику капитализма хотелось бы оставить в стороне, чтобы сосредоточиться на техниках конструирования тела, технической настройке перцепции и режимах жизни высокотехнологического субъекта. Современные компьютерные игры являются лабораториями по испытанию и формированию тел со специфическим набором перцептивных навыков.

Лейтмотивом данной статьи можно назвать исследование перцептивных режимов тела геймера, которые определяются интерфейсами и контроллерами. В эти технические инстанции уже встроены определенные интерпретации тела и способы действия, которые предполагают освоение специффической перцептивной грамматики и которые не всегда попадают в поле нашего внимания, заслоняемые сюжетом, правилами игры, графическим дизайном или аффордансами.

Итальянскому неомарксисту Паоло Вирно принадлежит мысль о связи понятий «биополитика» и «рабочая сила» (Вирно, 2013, сс. 97-98): в его несколько упрощающей интерпретации говорится, что «рабочая сила» является носителем возможностей, это - воплощенный dynamis, нематериальное сокровище, за которым охотится капиталист. В силу того, что капиталист заинтересован в рабочей силе, ее преумножении и сохранении, в XVIII веке появляются первые биополитические институты, реализующие эти задачи (напр., демографические институты, статистика и др. ${ }^{1}$ ). Связь между «биополитикой» и «рабочей силой», по всей видимости, есть, но эта редукция переподчинение биополитической проблематики марксистскому аналитическому аппарату (Вирно отсылает читателя к «Капиталу» К. Маркса) - обедняет понятие «биополитики». События недавнего времени - пандемия коронавируса - и вовсе делают ее ненадежной, поскольку экономические измерения биополитики ушли на периферию, уступив место риторике безопасности, контроля и чрезвычайного положения. Однако тезис о том, что человеческое тело - исток возможностей (dynamis), позволяет прояснить установки современного геймдизайна, его идеологическую подоплеку, пристрастие к нейробиологическому дискурсу и т. п.. Так, геймдизайнеры зачастую исходят из квантифицируемого представления о теле, которое - из этой перспективы - надо правильно рассчитывать и настраивать.

1 Как известно, впервые эту тему начинает разрабатывать М. Фуко во второй половине 1970-х гг. См., например, лекцию от 17 марта 1976 года из курса «Нужно защищать общество», где предлагается набросок исследования биовласти (Фуко, 2005, сс. 253-278). 
Например, на современном этапе развития игровой индустрии можно говорить о колонизации осязания: все больше игр - в VR и мобильном гейминге - ориентированы на тактильную перцепцию ${ }^{1}$ (что в очередной раз вынуждает указывать на ограниченность термина «видеоигры» - в современных играх много невизуального перцептивного опыта).

Итак, ключевые пункты движения - исследовать перцептивные режимы тела геймера, их связь с интерфейсами и контроллерами, задающими координаты нашей жизни в медиареальности, рассмотреть поворот к осязанию в современном геймдизайне.

Карта:

1) Компьютерные игры - это биополитические машины (интерфейсы игр - диспозитивы), регулирующие наш образ жизни, вовлекающие тело в новые перцептивные режимы, встраивающие дисциплинарные механизмы в тела. Здесь надо различать изображение биополитики в играх и организацию жизни геймера через интерфейсы и контроллеры, это две разные технологии первая показывает, вторая воздействует.

2) Интерфейсы создают мультисенсорную перцепцию. Практически нет регистров чувственности, которые были бы исключены из переработки в интерфейсах и контроллерах игр. Более того, вопрос всегда стоит так: какие еще интерфейсы и контроллеры нужны, чтобы опыт был более реальным и непосредственнымм?

3) На сегодняшний день в игровой индустрии активно прорабатывается осязание (через различные хаптические технологии), поэтому в последней части статьи вводится концепт «образприкосновение», схватывающий эту ситуацию.

Основные ориентиры читателю предложены: остается надеяться, что эта карта поможет разобраться в структуре текста.

Прежде чем перейти к основному размышлению, стоит еще раз подчеркнуть: то, что мы чувствуем, знаем и понимаем в цифровой реальности, задается интерфейсами и контроллерами, поэтому мы неизбежно что-то не чувствуем, не знаем и не понимаем. Интерфейсы и контроллеры, а также формируемые ими режимы восприятия и понимания по этой причине необходимо исследовать.

1 Эта тенденция в целом характеризует современные медиа: так, ряд моделей iPhone поддерживает функцию 3D Touch, позволяющую настраивать уровень тактильного отклика устройства. См. подробнее на сайте: https://support.apple.com/ru-ru/HT205056 


\section{BIOGAMING: PLAGUE INC., ВIO INC. И COVID-19 ${ }^{1}$}

Цель игры Plague Inc. (2012) от компании Ndemic Creations уничтожение человечества. Играть надо за возбудителя болезни (бактерия, вирус, грибок, паразит и т. д.), чтобы путем различных мутаций усилить болезнь, разнообразить способы ее распространения, повысить заразность, летальность и т. п. и уничтожить всех людей на Земле ${ }^{2}$. Этот разрушительный итог не мешает игре быть проводником биополитической риторики безопасности, рассказывать о том, как функционируют эпидемии и почему необходимы те или иные меры защиты ${ }^{3}$. Более того, в разгар пандемии COVID-19 весной 2020 года разработчики анонсировали режим игры, который, напротив, позволит игроку спасти человечество от заразы. Plague Inc. представляет собой постапокалиптическую грезу, в ироничном ключе позволяющую проиграть гибель человечества. Ироничная атмосфера, правда, тускнеет, когда заголовки обычных новостей напоминают заголовки новостей из Plague Inc. Компания Ndemic Creations даже выделила 250 тыс. долларов на борьбу с COVID-19, заботясь о своей репутации, после того как игра в феврале 2020 года пропала из магазинов мобильных приложений в Китае.

«Восемь лет назад я и не думал, что реальный мир станет похож на Plague Inc. или что Plague Inc., будет помогать многим игрокам пережить настоящую пандемию, - отметил Джеймс Воган (James Vogan), создатель Plague Inc. - Мы гордимся тем, что можем поддержать жизненно важную деятельность CEPI и BO3, пока они ищут вакцину от COVID-19» (Михайлова, 2020).

Игра Bio Inc. (2017) - своеобразный клон Plague Inc. - от DryGin Studios идет еще дальше: здесь та же стратегия разрушения применя-

1 Этот текст писался для тематического номера Galactica Media в декабре 2019 года (приглашенные редакторы - А. Р. Латыпова и М. М. Скоморох), однако закончить в срок его тогда не удалось. С тех пор мир столкнулся с пандемией COVID-19, что перевело воображаемый апокалипсис и биополитические процедуры, отображенные в этих играх, в офлайн-формат. На этом фоне некоторые механики Plague Inc. и Bio Inc., рассмотренные в первом варианте статьи, стали выглядеть более жутко, зловеще (Фрейд). После паралича, охватившего нашу жизнь в период пандемии, и личных трагедий механики Plague Inc. и Bio Inc. смотрятся как опережающее (а потому - неизбежно искаженное) отражение всеобщего биополитического (и экзистенциального) переживания. В них мы узнаем то, что случилось в период пандемии в 2020 году, но этот опыт более не кажется забавным и смешным. История произошла дважды: сначала - в виде фарса (в игре), а затем уже - в виде трагедии (в реальности). Такова предвосхищающая (и программирующая) сила современных медиа. В итоговый вариант статьи были внесены правки, учитывающие опыт пандемии, развития игровой индустрии в 2020-2021 гг., а также тексты, вышедшие за это время, хотя основные тезисы не претерпели изменений.

2 Официальный сайт игры: https://www.ndemiccreations.com/en/22-plague-inc

3 Поскольку назвать болезнь в игре можно как угодно, например «жизнь» или «любовь», то финальный титр может быть довольно комичным: «Победа! Любовь уничтожила всю жизнь на Земле». 
ется не к человечеству в целом, а к отдельному человеку: надо развить у пациента болезнь, которая в конечном счете его убьет. Эта игра выполняет функцию негативного просвещения, информируя игрока о том, что сопротивление прививкам, страх перед больницами, неправильное питание, курение и др. приближают печальную развязку. B Bio Inc. в процессе игры надо переключаться между различными системами организма («Кровообращение», «Дыхание», «Нервы», «Мышцы», «Почечная [система]», «Скелет», «Пищеварение»), чтобы собирать в этих вкладках «био очки» для последующей «покупки» на них: 1) болезней для жертвы (бронхит, рахит, остеопороз, дефицит калия, бессонница, астма, стресс, нефрит и т. п.); 2) факторов риска (лишний вес, наследственность, недоедание, трудоголик, обезвоживание и т. п.); а также 3) преград к выздоровлению (неверный диагноз, плохие врачи, забастовка медсестер, нозокомефобия ${ }^{1}$ и т. п.). Иногда в дело могут вступить случайные события: так, по ходу игры всплывает сообщение, что у жертвы был незащищенный секс, после чего игрок крутит «колесо болезней» и жертва может заразиться заболеванием, передающимся половым путем. По ходу игры геймер видит, как снижается эффективность систем организма (от 100\% до нуля): падение работоспособности систем отображается и визуально (органы окрашиваются в черный цвет, меняется ритм пульса и др.). Со временем жертва замечает болезнь и обращается к доктору, после чего игроку необходимо эффективно препятствовать лечению: игра превращается в увлекательное соревнование с медицинской и иммунной системой (иммунитет здесь визуализирован в виде щита). Кто успеет быстрее: болезнь или врачи ${ }^{2}$ ?

Plague Inc. и Bio Inc. через геймплей представляют биополитические процедуры, контроль над индивидуальным телом и телом рода (населением), а также вывернутую наизнанку логику заботы, когда вместо того, чтобы «инвестировать жизнь от края до края» (Фуко, 1996, c. 244), надо ее уничтожать. Эти игры вполне могут быть рассмотрены через оптику «процедурной риторики», т. е. через то, как они с помощью процедур передают игрокам определенные сообщения (Bogost, 2007). Геймплей здесь действительно сообщает игрокам некоторые идеи (Ароневич, 2016), однако биополитический дизайн компьютерных игр не сводится к подобным сообщениям: он в большей степени связан с тем, как само тело игрока включается

1 Боязнь медицинских учреждений.

2 В 2018 году в игровом магазине Steam появилась новая - дополненная и переосмысленная версия этой игры Bio Inc.: Redemption (2018), в которой можно не только убивать пациента, развивая его болезни, но и спасать его, выбрав сторону врачей: https:/store.steampowered.com/ app/612 470/Bio_Inc_Redemption 
в игровые процедуры. Геймеру сообщается определенный ритм и стиль жизни, техники тела, его окружают вниманием и заботой (например, для игроков выпускают специальные линейки кресел, клавиатур, компьютерных мышей, наушников, которые обеспечивают максимальные погружение и комфорт). Если эффективность процедурной риторики ограничена знанием игровых конвенций, нарративов, визуального языка игр и может не сработать в том или ином случае, то проработка телесности в процессе игры неизбежна. Тело геймера принадлежит интерфейсам, т. е. биополитические процедуры буквально разворачиваются в нем.

Игры, подобные Plague Inc. и Bio Inc., позволяют в шутливой форме примерить на себя роль нечеловеческого актора - болезни - и снять напряжение в трансгрессивном жесте ${ }^{1}$. Они дают понять, как работают биополитические процессы, представляют их в ясной визуальной и нарративной форме, предъявляют в компактном формате интерфейсов. В ходе игры происходит включение геймера в среду интерфейсов, в их соматическую грамматику. Иными словами, интерфейс/ контроллер - это диспозитив, т. е., согласно определению, «вещь, обладающая способностью захватывать, ориентировать, определять, пресекать, моделировать, контролировать и гарантировать поведение, жестикуляцию, мнения и дискурсы живых людей» (Агамбен, 2012, с. 26). Можно сказать, что в процессе игры на машину тела наносится текстура интерфейсов, что напоминает установку делезианского soft'a на картезианский hard ${ }^{2}$. Биополитические процедуры встраиваются в тело игрока, который, осваивая контроллеры (мышь с клавиатурой, геймпад, тачскрин и т. д.) и способы интеракции, превращается в главную платформу для биополитических инвестиций. Закономерно, что в игровой форме (как, впрочем, и в традиционных медиа: литературе, кино, сериалах) задолго до новостей о COVID-19 уже была разыграна биополитическая фантазия о чрезвычайном положении на фоне пандемии.

1 Например, в Bio Inc. можно задать любое имя пациенту («имя жертвы» на языке игры) - и тем самым в символическом формате погасить рессентиментарное чувство. Отчасти это похоже на то, как в азиатских компаниях сотрудники снимают напряжение, когда в перерывах бьют деревянными мечами по куклам, воображая своих боссов, топ-менеджеров и т. п.

2 Ср. с описанием тела в китайской медицине эпохи Мин, где энергетическая система, прописанная поверх физического тела, определяет его реальность: «Тело или, точнее, телесность, пустотное “тело без органов” - ключевая философема китайской традиции. <..> В распыленности “тела Дао” исчезает противостояние сознания и плоти, и это единение духа и вещества засвидетельствовано, помимо прочего, образом тела в китайской медицине, лишенном анатомии, сведенном к хаотически сложной геометрии “энергетических каналов”, и употреблением китайцами понятия “сердце” для обозначения разумного начала в человеке. Самое сознание китайские ученые соотносили с токами крови и лимфы» (Малявин, 2008, сc. 8384). 
В принципе, несложно понять, как выстраивать «оборону против биовласти на границе собственного тела» (Медведев, 2018), когда речь идет о контроле над ним со стороны государства, например устраивать голодовки или заниматься экстремальным спортом, превращая тело в трибуну для перформативного высказывания, но сопротивляться биополитическим процедурам, которые вшиты в игру, а через нее инсталлированы в тело, которые сопряжены с желанием и соблазном, гораздо труднее. Риск, аффект, удовольствие и боль, на которых строятся многие игры, притягательны. Игра соблазняет, вынуждая держать тело в тонусе и адекватности инстанциям управления - контроллерам, ее власть - лишь по видимости мягкая - держится на желании. Игровые контроллеры и интерфейсы легко становятся формами самоконтроля, поскольку обещают исполнить наши желания. В игровой форме они уже сняты как исполненные. Здесь располагаются самые современные техники сборки тела ${ }^{1}$ : в конечном счете гейминг превращается в биополитический процесс, поскольку в ходе игры не только демонстрируются те или иные концепты, связанные с темой биополитики, но они, встроенные в интерфейсы, становятся частью самой игры (частью тела игрока и формой его жизни).

\section{БИОМЕТРИЧЕСКИЕ ИНТЕРФЕЙСЫ: ИНКОРПОРАЦИЯ БИОПОЛИТИКИ}

Часто аналитики говорят о том, как биополитические процессы представлены в медиа: в кино, литературе, играх, т. е. говорят о содержании, которое передают медиа, о той рефлексии, которая культура

1 В самом общем виде под «сборкой тела» можно понимать комплекс практик, техник, отношений, которые организуют тело. С одной стороны, тело кажется самым «природным», что есть в человеке. С другой - тело конструируется культурой, т. е. оно является неестественным (или даже противоестественным) объектом, который колонизирован различными агентами культуры, инстанциями власти, техническими операторами. Эта тема затрагивалась во многих классических работах, однако последовательно ее разрабатывают после Ф. Ницше, М. Мосса («Техники тела»), М. Мерло-Понти и др. Так, например, у Ж. Делеза и Ф. Гваттари организм как способ сборки (ассамбляжа) тела становится основной мишенью для критики, а мотив дезорганизации тела, или разучреждения организма, соответственно, становится политической и философской задачей. М. Фуко - вслед за Ницше - говорит о различных дисциплинарных механизмах сборки тела. В российском контексте эти темы разрабатывал В. А. Подорога («Феноменология тела»). Современный российский медиафилософский дискурс (В. В. Савчук, К. П. Шевцов, К. А. Очеретяный и др.) рассматривает ассамбляж/сборку тела в контексте его включения в различные медийные, топологические, технические инстанции. В данной статье исследуются сборки тела геймера в процессе взаимодействия с интерфейсами и игровыми контроллерами. Стоит также отменить позицию петербургского философа Н. А. Грякалова, который, размышляя об антропологии измененных состояний сознания, писал: «Человеческий мир ставит система денатуратов - антропогенных “машин памяти”, которые не дают пропасть той тревоге, что была вчера» (Грякалов, 2017, с. 13). Н. А. Грякалов пишет о «ритуальной ректификации души» и сборках «человека в духе», однако его тезис идеально ложится и на тему сборки тела. 
производит через медиа, но не обращают внимания на роль самих медиа в биополитическом процессе. Уже М. Маклюэн отмечал, что говорить стоит прежде всего не о содержании, а о самом посреднике (Маклюэн, 2011). Поэтому рассмотреть стоит то, как медиа (в данном случае - компьютерные игры) включают нас в биополитику. Разработчики компьютерных игр давно экспериментируют с нашими телами. Так, например, можно вспомнить игру Nevermind (2015), которая использовала биоотлик для настройки уровня сложности:

\begin{abstract}
«Искусственный интеллект предполагает любое "разумное” поведение техники, т. е. когда она реагирует на пользователя, подстраивается под него, как если бы она могла чувствовать, желать, принимать решения. Так, игра Nevermind (2015) меняет уровень сложности в зависимости от реакций игрока: если он дал волю страху, игра станет сложнее, если ему удалось успокоиться, игра сделается легче. Смарт-объекты современного мира немыслимы без искусственного интеллекта» (Латыпова, 2019, с. 50).
\end{abstract}

С развитием игровой индустрии такие локальные эксперименты становятся все более привычными. Скоро контроллеры в автоматическом режиме будут аккумулировать данные о пользователях для модуляции игровых переживаний и настройки сложности. Сейчас этот опыт имеет технологические ограничения, но определенные шаги по все большему вовлечению тела геймера в цифровую среду и его перестройке уже сделаны.

После выхода летом 2020 года консоли нового поколения от PlayStation (PS5) с геймпадом DualSense произошла очередная трансформация тела игрока. На официальном сайте компании сказано, что «беспроводной контроллер DualSense для PS5 оснащен реалистичной тактильной отдачей, динамическими адаптивными триггерами и встроенным микрофоном в сочетании с оригинальным дизайном» ${ }^{1}$. Адаптивные курки и тактильная отдача геймпада позволяют ощутить игровую среду: отдачу оружия, силу удара, рукопожатие, скорость, натяжение тетивы лука и т. п.. DualSense пока не собирает данные о состоянии игрока, не считывает его биометрические параметры, но, вероятно, эти функции будут реализованы в будущих контроллерах от PlayStation, Microsoft и других компаний. Если судить по патентам, именно к этому готовится игровая индустрия: давно разработаны контроллеры, учитывающие движение тела (Wii Remote, Kinect), шлемы, куртки (pneumatically-actuated jacket) и перчатки, обес-

1 См. описание на официальном сайте: https:/playstation.com/ru-ru/accessories/dualsense-wireless-controller 
печивающие контакт с виртуальной реальностью ${ }^{1}$. До внедрения биометрических интерфейсов, которые уже есть в смартфонах, компьютерах, фитнес-трекерах, в процесс игры остался один шаг. После этого геймпад, считывая пульс игрока или частоту его дыхания, будет корректировать сложность игры (и давать рекомендации на будущее, сколько нужно сжечь калорий, чтобы игра не вызывала проблем с сердцем или одышки). Неигровые устройства уже выполняют эти функции, но биометрия пока не стала всеобщей основой геймплея. Когда это случится, привычными станут следующие ситуации: не удалось снизить частоту сердцебиения в сражении с боссом и ваш аватар понес больший урон. Подобные технологические настройки тела формируют разветвленную сеть биополитических процедур ${ }^{2}$, и они только укрепились в разгар пандемии COVID-19 в связи с переводом работы, учебы, отдыха в дистанционный формат.

П. Пресьядо, отрицательно оценивая дистанцию, производимую в медиа, назвал современную ситуацию «телекапитализмом»³:

«Телескоп. Телепатия. Телеграф. Телеграм. Телефон. Телевидение. Телефакс. Телефильм. Телероман. Телеассистент. Телесекс. Тележанр. Телеклуб. Телетруд. Телемарафон. Телебанк. Теледом. Телефото. Телеуправление. Телегид. <...> Телевидение - это состояние, при котором далекое оказывается близким, а близкое - далеко. Но если все наше внимание будет сосредоточено на том, что далеко, то, что будет с тем, что рядом?» (Пресьядо, 2021).

В сложившейся ситуации легко говорить о негативных эффектах, но критика теле/медиакапитализма строится на - наивной - вере в реальность, которая не зависит от медиа. Дж. Болтер и Д. Грусин отмечают, что эта установка является более или менее естественной в нашей работе с медиа, поскольку мы хотим получить амедиальный опыт (на языке Канта - прорваться к вещам-в-себе), окружая себя все более сложной системой посредников (такова, по мысли американских

1 Об этих и других контроллерах регулярно пишут в профильной прессе, а также на сайтах разработчиков. Из свежих примеров можно вспомнить VR-контроллер DecaMove, который «отслеживает движения тела независимо от направления взгляда» (Рассказов, 2021). O конструировании эстетического - чувственного - опыта с помощью подобных технических устройств, а также о некоторых из устройств можно прочитать и в исследовательской литературе (см., например: Keogh (2018); Ленкевич (2019) и др.).

2 Дж. Агамбен в схожем ключе говорит о формировании «идентичности без личности», когда машина опознает и признает меня по внеличностным, чисто биологическим параметрам (Агамбен, 2014).

3 П. Пресьядо в своей заметке использует как существующие слова с приставкой «теле-», так и конструирует новые: в первую очередь приставкой подчеркивается дистанция, но с тем же основанием можно говорить и о «медиакапитализме». Как не раз отмечал директор Центра медиафилософии (ИФ СПбГУ) В. В. Савчук количество слов с приставкой «медиа-» растет экспоненциально каждый год. 
философов, двойная логика ремедиации (Bolter \& Grusin, 1999)). Из этого можно сделать парадоксальный вывод, что самый естественный, подлинный, амедиальный опыт для нас достижим только посредством медиа. Посредством огромного количества медиа - их всегда будет для этого недостаточно.

\section{ЧТО ЧУВСТВУЕТ ТЕЛО, ВКЛЮЧЕННОЕ В ИГРУ?}

Учитывая создание новых контроллеров, все больше вовлекающих тело в игру, а также тонкую настройку и модуляцию чувств, происходящую в ее процессе, уместнее спросить: а что не чувствует тело, включенное в игру?

В 2013 году появилась альфа-версия игры The Way (2013), которая до сих пор в этом начальном, плачевно-безвестном состоянии и пребывает ${ }^{1}$. Тем не менее игра позволяет пережить особый опыт коммуникации и построения цифровой чувственности. Игра кооперативная: для того чтобы в нее сыграть, нужен напарник, выбирающийся наугад из числа желающих (отчасти в этом причина упадка The Way, поскольку игроков, которые хотят вновь погрузиться в игровую среду и решить те же самые головоломки, мало). Кооперация в игре организуется только через телесные жесты аватаров. Каждый из участников видит только половину элементов игры - и должен подсказывать напарнику, как преодолевать препятствия: игроки должны подсказывать друг другу решения головоломок, способы обойти препятствия, указывать путь. При этом голосовой и текстовый чат отсутствуют. Игра выбрасывает нас на нулевой уровень коммуникации, где язык, подобно тому как описывает этот процесс Э. Кассирер в первом томе «Философии символических форм» (Кассирер, 2002), зарождается из указательных местоимений (в игре буквально руками аватара указывается направление движения $\left.{ }^{2}\right)$ и т. п. Только после прохождения всех головоломок игроки получают дополнительную возможность коммуникации - карту мира, на которой можно обозначить место своего проживания или написать что-то на память и сделать скриншот.

Вывод, который можно сделать после прохождения The Way: тело, включенное в игру, чувствует то, что позволяют ему интерфейсы. Предельной иллюстрацией здесь будет берлинский аркадный автомат

1 Благодарность за знакомство с проектом я выражаю А. Д. Муждабе, редактору gamestudies.ru и сотруднику ЛИКИ. На данный момент существует довольно много кооперативных игр головоломок, например серия We Were Here (2017-2021), но способы коммуникации в них принципиально иные.

2 Подобная система жестов присутствует и в других игровых проектах, например в The Endless Forest (2005-2012), LittleBigPlanet (2008) или Dark Souls (2011). Кроме того, игроки многих мультиплеерных игр вырабатывают невербальные способы коммуникации, но они, как правило, не являются основой геймплея. 
«Болетрон» (PainStation), на котором можно сыграть в Pong (1972), за каждую ошибку получая порцию боли (удар хлыстом, электрическим током и т. п.). В этом издевательском художественном артефакте, который до предела доводит логику интеракции нашего тела с игровыми интерфейсами и в некоторой степени варьирует тему мазокорных игр (Скоморох, 2016), тело, включенное в игру, становится объектом непосредственных воздействий и ярких болевых ощущений. Тело в PainStation является частью игровой машины: границы его чувственности определяются как мазокорными механиками, так и игровыми контроллерами (тепловая панель, электропроводящие элементы, хлыст, рычаги управления). Современные VR/AR-игры, использующие, например, контроллеры Kinect, Nintendo Wii или «колесо» в Ring Fit Adventure $(2019)^{1}$, в которых аватаром (и контроллером/интерфейсом) становится тело игрока, конструируют более сложную чувственность, чем игры предыдущих поколений, где управление осуществлялось с помощью джойстика или геймпада.

Простой ответ на вопрос, что не чувствует тело, включенное в игру, такой: вкус ${ }^{2}$. На данный момент практически все чувственные восприятия моделируются с помощью оригинальных технических устройств. Прежде всего речь идет о 1) визуальном опыте (графиика стала визитной карточкой компьютерных игр и перешла из игрового формата в кино и другие медиа); 2) звуках ${ }^{3}$; 3) вибрации и тактильных ощущениях (вплоть до новшеств контроллера DualSense); 4) чувстве равновесия, скорости и т. п., связанных с вестибулярным аппаратом (например, в VR-проектах); 5) есть технические девайсы, позволяющие моделировать запахи: так, маска FeelReal ${ }^{4}$ позволяет чувствовать запахи и прикосновения к лицу пользователя. Стоит отметить, что в последние годы усилия разработчиков направлены на тактильную сферу, следующие шаг - создание доступных большой аудитории девайсов, моделирующих запахи (пока они не очень распространены) и вкус (фактически рабочих прототипов контроллеров в этой области

1 Контроллер буквально напоминает рулевое колесо, которое надо крутить в воздухе, чтобы преодолевать препятствия.

2 В играх пока не используются и более специфические - нечеловеческие - формы чувственности, такие как эхолокация или магниторецепция, однако для виртуальной реальности разрабатываются отдельные проекты, которые позволяют моделировать эти чувства.

3 На сегодняшний день визуальная и звуковая среда компьютерных игр исследованы хорошо. Этим заняты не только зарубежные, но и отечественные исследователи, например, есть актуальные работы, посвященные перспективе в играх от первого лица (Муждаба, 2019), геймплейной функции звука (Кириченко, 2019) и др. Поскольку разработчики расширяют перцептивный репертуар игр, вероятно, стоит наперед продумывать формы цифровой чувственности (не только осязание, с которым связаны текущие эксперименты игровой индустрии, но, возможно, и другие).

4 Сайт проекта: https://feelreal.com 
нет) $)^{1}$. Игровые контроллеры предлагают геймеру не только широкий спектр чувственных впечатлений, но и чувственных удовольствий, вплоть до сексуальных (есть специальные контроллеры для секс-игр (Sicart, 2017)).

Рене Декарт, разбираясь в первом размышлении «Медитаций...» с тем, что может быть подвергнуто сомнению, говорит о том, что чувства ненадежны, ибо могут обманывать (в пределе все может быть сном, и тогда чувства лгут постоянно):

«Без сомнения, все, что я до сих пор принимал за самое истинное, было воспринято мною или от чувств, или через посредство чувств; а между тем я иногда замечал, что они нас обманывают, благоразумие же требует никогда не доверяться полностью тому, что хоть однажды ввело нас в заблуждение» (Декарт, 2006, с. 141).

Опыт (игровых) медиа говорит, что чувства не только могут вводить нас в заблуждение и предлагать недостоверный опыт, они являются конструктом от начала и до конца, и наше восприятие целиком зависит от тех инстанций, которые мы используем контроллеров и интерфейсов. Аватар в The Way не отождествлен в игре с телом геймера, он не дублирует наши указательные жесты, но этот разрыв вполне может быть преодолен в VR-пространстве. Даже простое исполнение команд управления, пресловутой комбинации клавиш WASD, предполагает, что игрок усвоил игровые конвенции и техники тела, в VR-среде эта колонизация тела геймера игровыми знаками становится более очевидной. Если в разрыве между тем, что репрезентируется на экране, и действиями, которые совершает игрок, манипулируя контроллерами, еще разворачивается биополитическое сражение за тело, то в VR и AR само тело становится агентом биополитики. Любая вера в естественную данность тела геймера разбивается, стоит только вспомнить, как трудно освоить новый для себя контроллер или тип интерфейсов (скажем, перейти с клавиатуры и мыши на геймпад и обратно, поэтому можно говорить об особой «игре тел», связанной со сменой контроллеров (Keogh, 2018)). Подобная дисциплинарная настройка тела является частью биополитического дизайна компьютерных игр, но началась она намного раньше, по крайней мере, в XVII-XVIII вв., в эпоху бурного расцвета дисципли-

1 Игровая индустрия имеет широкие возможности для экспериментов с чувственностью и большое число добровольцев, которые испытывают новые технические аппараты. Пути к этому высокотехнологическому телу прокладывают не только разработчики игр, но и художники, имплантирующие в свои тела гаджеты для расширения перцептивного диапазона и связи с периферическими устройствами, и обычные пользователи, осваивающие новые интерфейсы, поэтому уже сейчас можно говорить о «высокотехнологических формах чувственности» (Ленкевич, 2020). 
нарных технологий (Фуко, 1999), и была встроена в последующие технические диспозитивы, в том числе и в контроллеры ${ }^{1}$.

\section{ОБРАЗ-ПРИКОСНОВЕНИЕ}

Валерий Савчук в статье о перформансе задает вполне уместный вопрос «Куда исчезает перформанс?». Он действительно заставляет задуматься, тем более, что ответ на этот вопрос есть. Если проследить вехи жизненного пути перформанса, который «дает максимально приближенную к тактильности картину времени» (Савчук, 2017), то вместе с автором мы придем к неутешительному выводу «перформанс сегодня стал излишне адаптирован к клубной культуре, к театру, танцу и популярной эстраде» (Савчук, 2017). Перформанс вымирает также и под натиском аудиовизуальных медиа, цифровой культуры, предлагающей новые формы телесного присутствия. Вопрос, заданный автором, абсолютно точен - и на него есть столь же точный ответ: «Перформанс исчезает в компьютерные игры» ${ }^{2}$.

В первую очередь он исчезает в игры с виртуальной и дополненной реальностью (VR и $\mathrm{AR}$ ), но также в игры с использованием специальных контроллеров, подобных «колесу» для Ring Fit Adventure, которые превращают геймера в перформера ${ }^{3}$. В 2020 году появилась игра Half-Life: Alyx (2020), новая игра из серии Half-Life (1998-2020), которую игроки ждали около двенадцати лет. Примечательно в этой

1 Исследователь медиа и компьютерных игр К. А. Очеретяный предлагает расположить точку «изобретения тела геймера» в XIX веке в связи с появлением первых аркадных автоматов (slot machine), например «Колокола свободы» Чарльза Фэя (Очеретяный, 2014).

2 Несмотря на то что есть более благозвучные варианты этой фразы («перформанс уходит в компьютерные игры», «перформанс растворяется в игровом опыте» и т. д.), чтобы сохранить перекличку с вопросом В. В. Савчука, я предпочитаю говорить «...исчезает в...». Своей неправильностью/неказистостью эта фраза заставляет сделать паузу и поразмышлять над тем, что имеется в виду (подобно названию фильма «Как я провел этим летом?»).

3 В этой статье рассматривается телесная сторона игрового опыта, т. е. перформативность в данном случае подразумевает включение в игру тела, задействование соматического опыта игрока, а не специальную художественную практику. Следует отличать эту телесную перформативность игр от практики собственно художественных перформансов, которые происходят в компьютерных играх и игровых средах, например ироничные акции, повторяющие классические перформансы 1960-1970-х гг. в Second Life (2003) или антивоенные перформансы в Counter Strike (2000-2014). Художественные перформансы, как уже сказано, находятся за границами данного исследования, но о них можно прочитать в других аналитических работах (см., например: Янссон, 2013; Скоморох, 2014). Главное отличие перформативности игр от художественных перформансов в играх заключается в том, что в первом случае само тело игрока действует и собирается для того, чтобы игра состоялась, а во втором случае «перформансы... исполняются художниками посредством их аватаров» (Янссон, 2013), т. е. в первом случае работает тело игрока, во втором аватар художника. Само собой разумеется, первый опыт более распространен и характеризует игровую ситуацию в целом, а второй предполагает особую эстетическую фильтрацию геймплея. Все многопользовательские игры могут быть местом для художественного перформанса, но перформативность игр в целом проявляется не столько в художественных акциях и представлениях, а в той соматической работе, которая связана с организацией игры, освоением интерфейсов и контроллеров, физической стороной управления. 
игре то, что она была сделана для VR: если в предыдущие игры серии - Half-Life (1998) и Half-Life 2: Episode Two (2007) - можно было сыграть вполне привычным способом на клавиатуре и геймпаде, то HalfLife: Alyx - игра, использующая технологии виртуальной реальности. Только на момент выхода игры (март 2020 года) было продано более 500000 ее копий ${ }^{1}$, это довольно высокий результат для VR-игры. HalfLife: Alyx - всего лишь знаковый пример: на сегодняшний день рынок устройств виртуальной реальности не самый успешный, но несмотря на это многие пользователи приобретают устройства для VR и переживают немало телесных трансформаций с их помощью. Количество пользователей VR больше, чем художников-перформеров, т. е. это более распространенный опыт. У перформанса и VR-игр немало сходств:

«В перформансе тело участвует во всей своей полноте, во всех аспектах расположения в пространстве, так и нерасположения к нему, чувстве безысходности и покинутости, чувстве отсутствия реальных переживаний» (Савчук, 2017).

Палитра телесного опыта, доступная VR-перформерам, пока, конечно, беднее, чем аналогичная палитра перформанса или танца, но этот опыт тем и привлекает, что предъявляет меньше требований при вхождении в него. Например, зритель для игры вовсе не нужен, а в перформансе разделение на исполнителей и зрителей имеет, как пишут исследователи, принципиальное значение (Рыжакова \& Сироткина, 2016, с. 729) 2 .

Half-Life: Alyx и другие игры для виртуальной реальности - это современные перформансы с подлинными переживаниями новой реальности тела: органы периферических устройств соединяются с органами тел и создают серии соматических галлюцинаций. Здесь мы имеем дело с воображением тела геймера, с вхождением в образ, телесной коммуникацией. Результат подобной коммуникации - смешение порядков представления и интеракции, визуализации и взаимодействия, синтез репрезентации и инкорпорации, который

1 См., например, новость на сайте Playground от 23 марта 2020 года: https://playground.ru/ half_life_alyx/news/prodano_bolee_500_000_kopij_half_life_alyx-715538\#

2 Если развивать аналогию между перформансом и телесной включенностью геймера в игру, можно вспомнить перформанс «Родина-мать» Лизы Морозовой (2014 года), в котором обнаженная художница перемещалась по галерее с замотанной скотчем головой, скотчем же к голове был примотан игрушечный танк. Антивоенный пафос перформанса вполне очевиден, менее же очевидно его сходство с опытом использования VR-шлема (с тем же эффектом экранирования мира и медиальной слепотой). На фоне появления современных VR-устройств этот обезоруживающий перформанс смотрится вдвойне актуально. Подробнее см.: http://artuzel.com/content/liza-morozova-performans-rodina-mat 
является особой чертой биополитического дизайна современных интерфейсов. В играх с традиционным управлением есть «зазор» между телом игрока и аватаром, в VR / AR-играх этот разрыв сокращается. Следующий шаг - нейроинтерфейс, который позволит нам ощутить себя в другом теле без какого-либо физического напряжения. Декарт в свое время отвергал возможность

«сравнить себя с Бог ведает какими безумцами, чей мозг настолько помрачен тяжелыми парами черной желчи, что упорно твердит им, будто они - короли, тогда как они нищие, или будто они облачены в пурпур, когда они попросту голы, наконец, что голова у них глиняная либо они вообще не что иное, как тыквы или стеклянные шары; но ведь это помешанные, и я сам показался бы не меньшим безумцем, если бы перенял хоть какую-то их повадку» (Декарт, 2006, сс. 141-142).

В будущем для нас этот опыт вполне может стать тривиальным. Гастон Башляр однажды заметил, что оправданием для написания статьи может быть по крайней мере, новое слово, которое в ней вводится (Башляр, 2009, с. 369): итоговый концепт данного текста «образ-прикосновение» ${ }^{1}$. Мир современных медиа переживается кожей - мы живем в эпоху, которая как никогда сближается с архаикой по производству тактильного опыта:

«...ранние свидетельства сигнификации выдают способность, которая сегодня встречается крайне редко: способность почувствовать боль материала, на который наносятся знаки. Согласованность ощущений доходит до нерасторжимости. Разделение еще не свершилось: разделение между субъектом и объектом, которое запустит игру силы и власти. Границы как фильтр еще проницаемы. Сострадание камню, стене, поверхности, шкуре чутко к эффектам насилия, которое с определенного времени ассоциировалось с землепашцем. Потому предпочтение отдавалось тем комплексным знакам, которые имеют в себе свою, в конечном счете непреодолимую, противоположность - хаотическую субстанцию» (Кампер, 2010, c. 32).

Дитмар Кампер описывает сеть, в которой разнообразные акторы существуют на равных, а мастер ощущает материал, с которым взаимодействует ${ }^{2}$. Касаясь современных интерфейсов (сенсорный экран и т. п.), мы приближаемся к этому переживанию: здесь материал выступает в своей гладкой форме, еще нет риффления и рельефа -

1 По аналогии с концептами «образ-движение» и «образ-время» Ж. Делеза, введенных для проработки опыта кино, а также с концептом «if-образ» M. М. Скоморох, который используется для описания вариативности игровой перцепции (Скоморох, 2020).

2 Близкое ощущение фиксирует знаменитый тезис Протагора, точнее, вторая его часть: «Человек есть мера всех вещей, существующих, что они существуют, и несуществующих, что они не существуют». 
он скрыт на поверхности, испещренной знаками. Новые игровые аппараты и интерфейсы позволяют перенести эти знаки на наше тело. С учетом того, что самый быстрорастущий сегмент игрового рынка мобильный гейминг, ставка здесь делается именно на осязание, на вхождение в тактильный сенсориум (а также на ощущение положения в пространстве, кинестезию и др.), на «производство присутствия» - телесного опыта - в компьютерных играх (Ленкевич, 2019).

Воображение тела в нашу эпоху поддерживается аппаратами. Как было замечено:

«На новаторский способ производства тела в эпоху модерна первым указал Вальтер Беньямин. Обычно его статью воспринимают в качестве прогностического анализа произведения искусства в эпоху, когда стало возможно его воспроизведение. Однако более важным, в любом случае для нашей тематики, является его указание на то, что в настоящее время возник новый способ производства тела: техническое воспроизводство тел в визуальных медиа, особенно в фотографии, кино, телевидении и видео». (Гебауэр, 2013, сс. 98-99).

Доминирующим элементом в этом ряду стали игры, которые за счет различных технических эффектов создают новые тела. Например, вибрация геймпада задает не только новые способы ориентации в среде игры, но и новые сборки тела. Можно выделять различные геологические эпохи воображения тела ${ }^{1}$, здесь лишь стоит коснуться последней из них - современного этапа хаптических игр, в которых ключевая функция отводится прикосновению. Когда мы работаем с интерфейсами, образы-прикосновения инсталлируются в наше тело: здесь еще предстоит различить касания-реакции (на которых игры строятся сейчас) и касания-созерцания (которые будут в самом осязании открывать новые - оптические - функции). Ж. Делез, исследуя логику ощущения на материале живописи Ф. Бэкона, говорит об особой функции зрения - гаптической,

1 Эта тема, безусловно, требует отдельного разговора: коротко можно отметить, что речь идет о практиках и техниках (воображения) тела, включения его в образ. Тело геймера (как и тело пользователя других медиа) формируется задолго до появления первых компьютерных игр, поэтому законно говорить об археологии или геологии тела геймера. Например, как отмечалось выше, дисциплинарные техники, муштра и дрессура тела, которые Фуко относит к XVII-XVIII вв., являются важной вехой на пути к телу геймера. Без этой дрессуры, без нанесения знаков памяти на тело человека (Ницше, 1990, сс. 441-443) культура, в том числе и игровая, невозможна. Если, однако, говорить о собственно игровой культуре (и отсчитывать ее от появления первых игр), то здесь можно обнаружить смену техник тела, смену образов тела (игрок с геймпадом или джойстиком; игрок с клавиатурой и компьютерной мышью; игрок, погруженный в VR). Строгой последовательности здесь нет: слои накладываются друг на друга, переплетаются, исчезают, развиваются параллельно и т. д. Но мы можем отмечать ключевые точки, вокруг которых собирается игровой опыт (например, комбинация WASD или тактильная поверхность экрана на смартфоне). 
от которой отделена его оптическая функция (т. е. можно просто видеть, а можно схватывать вещь взглядом):

«...о гаптическом отношении можно говорить всякий раз, когда строгой субординации между рукой и глазом, ослабленного подчинения или виртуального сцепления нет, когда зрение открывает в себе собственную функцию осязания, принадлежащую только ему и отличную от его оптической функции. В этом случае можно сказать, что художник пишет глазами - в том смысле, что он осязает глазами. Гаптическую функцию непосредственно, сразу открывают во всей ее полноте древние формы, секрет которых мы утратили, - формы древнеегипетского искусства. Но она может быть и заново изобретена “современным” глазом исходя из неистовства и своеволия руки» (Делез, 2011, с. 161).

Касания-созерцания и другие «незаконные» смеси ощущений, такие как касания-звуки (музыкальных игр), касания-вибрации и др. развернут собственно тактильный опыт в новые форматы: уже сейчас довольно трудно раздробить опыт прикосновения и зрения в технологиях виртуальной реальности. Мы прикасаемся к сенсорным экранам смартфонов, тачпадам, тачскринам, скоро появятся и другие аппараты, подобные ShapeShift (прототип устройства, способного моделировать текстуры виртуальных объектов ${ }^{1}$ ) или Kissinger (девайс для смартфонов, позволяющий передавать поцелуи на расстоянии ${ }^{2}$ ), с помощью которых можно будет прикасаться к цифре, чувствовать ее ответные касания, удары, объятия, боль. Это уже не просто созерцание того, что есть на экране, но конструирование нового тела с новыми измерениями чувственного опыта. Не так давно ученые из США и Гонконга к огромному числу устройств, моделирующих тактильные переживания в виртуальной реальности, добавили интерфейс Haptic Skin, «хаптическую кожу» (Marsh, 2019), которая позволит испытать тончайшие нюансы прикосновений к цифровым объектам. В скором времени мы, возможно, будем напрямую сталкиваться с ними (или экранировать их с помощью антитактильных файерволов). Если раньше ассамбляж нашего тела с машиной преимущественно опирался на модель «зрение - рука - экран», то за последние годы моделей сборки стало больше. Прикосновение как основа геймплея (и - обратно - геймплей как способ создания тактильного опыта) задают новые координаты воображения нашего тела. На этом рубеже изобретаются новые приемы и техники биополитического дизайна, когда тело игрока технологически прорабатывается, а интерфейсы превращаются в формы чувственности, неотделимые от нашей жизни.

1 См. сайт ShapeLab: http://shape.stanford.edu/research/shapeShift

2 См. видео: https:/www.youtube.com/watch?v=5sfMBc7vVV0 
В конечном счете биополитические процедуры усваиваются игроком через овладение контроллерами и игровыми интерфейсами и поэтому уместно вернуться к вопросу, вынесенному в заглавие: а в своем ли мы пребываем теле? И ответ: конечно, да! В одном из них.

\section{ЛЮДОГРАФИЯ}

1) Bio Inc. (2017)

2) Bio Inc.: Redemption (2018)

3) Counter Strike, серия игр (2000-2014)

4) Dark Souls (2011)

5) Endless Forest, The (2005-2012)

6) Half-Life (1998)

7) Half-Life 2: Episode Two (2007)

8) Half-Life: Alyx (2020)

9) LittleBigPlanet (2008)

10) Nevermind (2015)

11) Plague Inc. (2012)

12)Pong (1972)

13) Ring Fit Adventure (2019)

14) Second Life (2003)

15) Way, The (2013)

16) We Were Here (2017-2021)

\section{БЛАГОДАРНОСТИ / АСКNOWLEDGMENTS}

Исследование выполнено при финансовой поддержке гранта РНФ. Проект 21-18-00 046 «Определение критериев визуального загрязнения окружающей среды».

The research was made with the financial support from RSF, project 2118-00 046 "The definition of criteria for visual pollution of the environment, SPBU". 


\section{Список литературы}

Bogost, I. (2007). Persuasive Games: The Expressive Power of Videogames. Cambridge, MA: The MIT Press.

Bolter, J. D., \& Grusin, R. (1999). Remediation: Understanding New Media. Cambridge, MA: The MIT Press.

Keogh, B. (2018). A Play of Bodies. How We Perceive Videogames. Cambridge, MA: The MIT Press.

Marsh, G. (2019). Haptic Skin' Creates Virtual Sense of Touch. Nature. doi: 10.1038/d41586019-03596-z

Sicart, M. (2017). Queering the Controller. Analog Game Studies, VII(II). Retrieved from https://analoggamestudies.org/2017/07/queering-the-controller

Агамбен, Дж. (2012). Что такое диспозитив? В Дж. Агамбен, Что современно? (сс. 1344). Киев: ДУХ І $\Lambda$ ТЕРА.

Агамбен, Дж. (2014). Идентичность без личности. В Дж. Агамбен, Нагота (сc. 78-90). Москва: Издательство Грюндриссе.

Ароневич, О. (2016). § 2. Как компьютерные игры передают идеи? В Медиафилософия ХІІ. Игра или реальность? Опьтт исследования компьютерных игр (сс. 4353). Санкт-Петербург: Фонд развития конфоликтологии.

Башляр, Г. (2009). Грезы и радио. В Поэтика грезы (сс. 369-374). Москва: РОССПЭН.

Вирно, П. (2013). Грамматика множеств: К анализу форм современной жизни. Москва: Ад Маргинем Пресс.

Гебауэр, Г. (2013). Тело, созданное аппаратами, и аппарат, создающий тело. Логос, (5), 97-107.

Грякалов, Н. А. (2017). Фигуры террора - 2. Санкт-Петербург: Издательство РХГА.

Декарт, Р. (2006). Размышления о первой философии. В Сочинения (сс. 132-185). Санкт-Петербург: Наука.

Делез, Ж. (2011). Фрэнсис Бэкон: Логика ощущения. Санкт-Петербург: Machina.

Кампер, Д. (2010). Знаки как шрамы. Графизм боли. В Тело. Насилие. Боль (сс. 30-46). Санкт-Петербург: Издательство РХГА.

Кассирер, Э. (2002). Философия символических форм. Том 1. Язык. Москва, Санкт-Петербург: Университетская книга.

Кириченко, В. (2019). Многоязычность компьютерной игры: О геймплейной функции звука. Международный журнал исследований культуры, (1), 102-112. doi: 10.24411/2079-1100-2019-00 008

Латыпова, А. Р. (2019). Игровой искусственный интеллект как медиум социального мира. Международный журнал исследований культуры, (1), 46-61. doi: 10.24411/2079-1100-2019-00 004 
Ленкевич, А. С. (2019). На пути к медиаэстезису: Производство присутствия в компьютерных играх. Международный журнал исследований культуры, (1), 2033. doi: 10.24411/2079-1100-2019-00 002

Ленкевич, А. С. (2020). Высокотехнологические формы чувственности. В Критика цифрового разума (сс. 126-144). Санкт-Петербург: Академия исследования культуры.

Маклюэн, Г. М. (2011). Понимание медиа: Внешние расширения человека. Москва: Кучково поле.

Малявин, В. В. (2008). Повседневная жизнь Китая эпохи Мин. Москва: Молодая гвардия.

Медведев, С. (2018). Биополитика авторитарного транзита. Извлечено от https:/ www.colta.ru/articles/society/20 042-biopolitika-avtoritarnogo-tranzita

Михайлова, В. (2020). Разработчик Plague Inc. Пожертвовал $\$ 250$ тысяч на борьбу с коронавирусом. Извлечено от https://app2top.ru/industry/razrabotchik-plague-incpozhertvoval-250-ty-syach-na-bor-bu-s-koronavirusom-162479.html

Муждаба, А. Д. (2019). Попробуйте повернуться: К генеалогии игровой перспективы от первого лица. Новое литературное обозрение, (158). Извлечено от https:// nlobooks.ru/magazines/novoe_literaturnoe_obozrenie/158_nlo_4_2019/article/ 21375/

Ницше, Ф. (1990). К генеалогии морали. В Сочинения в 2 томах (Т. 2). Москва: Мысль.

Очеретяный, К. А. (2014). Изобретение тела геймера. В Медиафилософия Х. Компьютерные игры: Стратегии исследования (сс. 252-274). Санкт-Петербург: Издательство Санкт-Петербургского философского общества.

Пресьядо, П. (2021a). Причудливый технопатриархат: Репродукция. Извлечено от https://centerforpoliticsanalysis.ru/position/read/id/prichudlivyj-tehnopatriarhatreproduktsija

Пресьядо, П. (2021b). Телекапитализм. Извлечено от https:// centerforpoliticsanalysis.ru/position/read/id/telekapitalizm

Рассказов, В. (2021). Открыт предзаказ VR-контроллера DecaMove. Извлечено от https://dtf.ru/hard/707 715-otkryt-predzakaz-vr-kontrollera-decamove-kotoryyotslezhivaet-dvizheniya-tela-nezavisimo-ot-napravleniya-vzglyada

Рыжакова, С. И., \& Сироткина, И. Е. (2016). Performance studies: Концепция и исследовательские подходы. Обсерватория Культуры, 13(6), 726-735. doi: 10.25281/2072-3156-2016-13-6-726-735

Савчук, В. В. (2012). Топологическая рефлексия. Москва: Канон+, Реабилитация.

Савчук, В. В. (2017). Куда исчезает перформанс? Художественньй журнал, (103). Извлечено от http://moscowartmagazine.com/issue/64/article/1346

Скоморох, М. М. (2014). Перформансы в онлайновых играх: К вопросу об отношениях между видеоиграми и искусством. В Медиафилософия Х. Компьютерные игры: Стратегии исследования (сс. 142-152). Санкт-Петербург: Издательство Санкт-Петербургского философского общества. 
Скоморох, М. М. (2016). § 21. Мазокор: Наследие Сада и Мазоха в компьютерных игpax. В Медиафилософия ХІІ. Игра или реальность? Опыт исследования компьютерных игр (сс. 371-392). Санкт-Петербург: Фонд развития конфоликтологии.

Скоморох, М. М. (2020). Алгоритмическая эстетика: If-образ как форма сопротивления исчислимости кода. В Критика цифрового разума (сс. 160-181). СанктПетербург: Академия исследования культуры.

Фуко, М. (1996). Право на смерть и власть над жизнью. В Воля к истине: По ту сторону знания, власти и сексуальности (сс. 238-268). Москва: Касталь.

Фуко, М. (1999). Надзирать и наказыьвать. Рождение тюрьмы.. Москва: Ad Marginem.

Фуко, М. (2005). Нужно защищзать общество. Санкт-Петербург: Наука.

Хайдарова, Г. Р. (2013). Феномен боли в культуре. Санкт-Петербург: Издательство РХГА.

Янссон, М. (2013). От Plaintext Players до Avatars Actors: Небольшое исследование на тему перформансов в онлайновых играх. Извлечено от https:/gamestudies.ru/ translations/performance/

\section{References}

Agamben, G. (2012). What is an Apparatus? In G. Agamben, What is Contemporary? (pp. 1344). Kiev: Spirit and NITEPA. (In Russian).

Agamben, G. (2014). Identity without the Person. In G. Agamben, Nudities (pp. 78-90). Moscow: Grundrisse Publishing House. (In Russian).

Aronevich, O. (2016). § 2. How do computer games convey ideas? In Media Philosophy XII. Game or Reality? Game Studies Experience (pp. 43-53). St. Petersburg: Fond of Conflictology Development. (In Russian).

Bachelard, G. (2009). Reverie and Radio. In The Poetics of Reverie (pp. 369-374). Moscow: ROSSPEN. (In Russian).

Bogost, I. (2007). Persuasive Games: The Expressive Power of Videogames. Cambridge, MA: The MIT Press.

Bolter, J. D., \& Grusin, R. (1999). Remediation: Understanding New Media. Cambridge, MA: The MIT Press.

Cassirer, E. A. (2002). Philosophy of Symbolic Forms. Volume 1. Language. Moscow, St. Petersburg: University Book. (In Russian).

Deleuze, G. (2011). The Logic of Sense. St. Petersburg: Machina. (In Russian).

Descartes, R. (2006). Meditations on First Philosophy. In Works (pp. 132-185). St. Petersburg: Science. (In Russian).

Foucault, M. (1996). Right of Death and Power over Life. In The Will to Knowledge: Beyond Knowledge, Power, Sexuality. Works of Different Years (pp. 238-268). Moscow: Castal. (In Russian). 
Foucault, M. (1999). Discipline and Punish: The Birth of the Prison. Moscow: Ad Marginem. (In Russian).

Foucault, M. (2005). Society Must Be Defended. St. Petersburg: Science. (In Russian).

Gebauer, G. (2013). Body Made by Machines and Body-Making Machine. Logos, (5), 97-107. (In Russian).

Gryakalov, N. A. (2017). Figures of Terror - 2. St. Petersburg: Publishing house RCHA. (In Russian).

Jansson, M. (2013). From Plaintext Players to Avatars Actors: A Short Survey of Online Gaming Performance. Retrieved from https://gamestudies.ru/translations/performance/ (In Russian).

Kamper, D. (2010). Signs as Scars. Graphism of Pain. In Body. Violence. Pain (pp. 30-46). St. Petersburg: Publishing house RCHA. (In Russian).

Keogh, B. (2018). A Play of Bodies. How We Perceive Videogames. Cambridge, MA: The MIT Press.

Khaidarova, G. R. (2013). Phenomenon of Pain in Culture. St. Petersburg: Publishing house RCHA (In Russian).

Kirichenko, V. (2019). Multilinguality of Computer Game. On the Gameplay Function of Sound. International fournal of Cultural Research, (1), 102-112. doi: 10.24411/20791100-2019-00 008 (In Russian).

Latypova, A. R. (2019). Game Artificial Intelligence as a Medium of Social World International fournal of Cultural Research, (1), 46-61. doi: 10.24411/2079-1100-2019-00 004 (In Russian).

Lenkevich, A. S. (2019). On the Way to Media Esthesis: Production of Presence in Computer Games. International fournal of Cultural Research, (1), 20-33. doi: 10.24411/20791100-2019-00 002 (In Russian).

Lenkevich, A. S. (2020). Hi-Tech Forms of Sensibility. In A Critique of the Digital Reason (pp. 126-144). St. Petersburg: Academy of Culture Research. (In Russian).

Malyavin, V. V. (2008). Everyday Life of China in the Epoch of Ming. Moscow: Young Guard. (In Russian).

Marsh, G. (2019). Haptic Skin' Creates Virtual Sense of Touch. Nature. doi: 10.1038/d41 586019-03 596-Z

McLuhan, G. M. (2011). Understanding Media. Moscow: Kuchkovo pole. (In Russian).

Medvedev, S. (2018). Biopolitics of Authoritarian Transit. Retrieved from https://www.colta.ru/articles/society/20 042-biopolitika-avtoritarnogo-tranzita (In Russian).

Mikhailova, V. (2020). Developer of Plague Inc. made the donation of $\$ 250000$ for the Fight Against Covid. Retrieved from website: https://app2top.ru/industry/razrabotchikplague-inc-pozhertvoval-250-ty-syach-na-bor-bu-s-koronavirusom-162 479.html (In Russian). 
Muzhdaba, A. D. (2019). Try to Turn: A Genealogy of First-Person View in Games. New Literature Review, (158). Retireved from https://nlobooks.ru/magazines/novoe_literaturnoe_obozrenie/158_nlo_4_2019/article/21375/ (In Russian).

Nietzsche, F. (1990). On the Genealogy of Morality. In Work in 2 Volunes (Vol. 2). Moscow: Mysl. (In Russian).

Ocheretyany, K. A. (2014). The Invention of the Gamer Body. In Media Philosophy X. Computer Games: Strategies of Research (pp. 252-274). St. Petersburg: St. Petersburg Philosophical Society. (In Russian).

Preciado, P. (2021a). Baroque Technopatriarchy: Reproduction. Retrieved from https:// centerforpoliticsanalysis.ru/position/read/id/prichudlivyj-tehnopatriarhat-reproduktsija (In Russian).

Preciado, P. (2021b). Telecapitalism. Retrieved from https://centerforpoliticsanalysis.ru/position/read/id/telekapitalizm (In Russian).

Rasskazov, V. (2021). Pre-order VR-controller DecaMove is Open. Retrieved from https:// dtf.ru/hard/707 715-otkryt-predzakaz-vr-kontrollera-decamove-kotoryy-otslezhivaet-dvizheniya-tela-nezavisimo-ot-napravleniya-vzglyada (In Russian).

Ryzhakova, S. I., \& Sirotkina, I. E. (2016). The Performance Studies: One Conception, Several Approaches. Observatory of Culture, 13(6), 726-735. doi: 10.25281/2072-3156-2016-136-726-735 (In Russian).

Savchuk, V. V. (2012). Topological Reflection. Moscow: Canon+, Reabilitation. (In Russian).

Savchuk, V. V. (2017). Where Has Performance Gone? Moscow Art Magazine, (103). Retrieved from http://moscowartmagazine.com/issue/64/article/1346 (In Russian).

Sicart, M. (2017). Queering the Controller. Analog Game Studies, VII(II). Retrieved from https://analoggamestudies.org/2017/07/queering-the-controller

Skomorokh, M. M. (2014). Performances in Online Games: To the Question of Relationship between Video Games and Art. In Media Philosophy X. Computer Games: Strategies of Research (pp. 142-152). St. Petersburg: St. Petersburg Philosophical Society. (In Russian).

Skomorokh, M. M. (2016). § 21. Mazocore: the Heritage of Sade and Masoch in Computer Games. In Mediaphilosophy XII. Game or Reality? Game Studies Experience (pp. 371392). St. Petersburg: Fond of Conflictology Development. (In Russian).

Skomorokh, M. M. (2020). Algorithmic Aesthetics: If-image as a Form of Code Countability Resistance. In A Critique of the Digital Reason (pp. 160-181). St. Petersburg: Academy of Culture Research. (In Russian).

Virno, P. (2013). A Grammar of the Multitude: For an Analysis of Contemporary Forms of Life. Moscow: Ad Marginem Press. (In Russian). 